\title{
Observations on an unusual enzyme distribution pattern in the colon of a case of familial polyposis with malignant changes
}

\author{
V. MAGGI AND A. P. WYATT \\ From Department of Cellular Pathology, Imperial Cancer Research Fund, Lincoln's Inn Fields, \\ London, and the Memorial Hospital, Shooters Hill, London
}

SUMMARY Acid and alkaline phosphatases, esterases, and $\beta$-glucuronidase were studied histochemically in the colon of a patient with familial polyposis in whom malignant changes had occurred. The acid hydrolases were found to be localized mainly in the supranuclear region of the cells of the epithelium of the normal mucosa. In the polyp epithelium these enzymes were found mainly in the basal areas of the epithelium at the junction between the latter and the lamina propria. In the cancer cells enzyme activity was decreased and distributed randomly.

Alkaline phosphatase was present only in the capillaries in the normal and the polypmucosa. In the cancer tissue this enzyme was found in the capillaries, the smooth muscle cells, and the invading cells of epithelial origin.

In a study of the enzyme patterns in human cancer it is of some interest to follow the changes taking place in a tissue which is undergoing malignant degeneration. It is well known that in cases of familial polyposis of the colon in which no therapeutic action is taken, carcinoma always develops, often at an early age (LockhartMummery, 1967). Aspecimen in which malignancy had developed offered a unique opportunity of studying in one patient the steps progressing to malignancy, as 'normal' mucosa, pre-malignant polyps, and frank carcinoma were all available.

\section{Clinical History}

The patient was a 43-year-old woman from a known polyposis family. Her mother, grandmother, and an aunt had died of large bowel carcinoma and her son was known to have polyposis. She had declined treatment until symptoms from a rectal carcinoma made operation imperative. A total proctocolectomy was carried out but she died with hepatic metastases 18 months later.

\section{Material and Methods}

Macroscopically the operative specimen was typical of polyposis coli with numerous polyps in the rectum and sigmoid colon. There was an obvious ulcerating carcinoma present in the rectum. Histological examination confirmed the diagnosis showing typical hyperplastic adenomatous polyps and a carcinoma in the rectum with involvement of one superior haemorrhoidal lymph node.

\section{HISTOCHEMISTRY}

Pieces of 'normal' mucosa, of polyps, and of malignant tissue were excised from the colon immediately after surgical removal. Each piece of tissue was cut into several blocks of about $0.5 \mathrm{~cm}^{3}$, which were fixed in $10 \%$ formaldehyde and rinsed for 18 hours in gum acacia-sucrose according to the method of Holt (1959). They were frozen in hexane precooled to $-70^{\circ} \mathrm{C}$ in an acetone-solid carbon dioxide bath, or processed for routine histological investigation. Sections (6-8 $\mu$ ) were cut in a cryostat and air dried. Acid and alkaline phosphatases and esterases were 
(a)

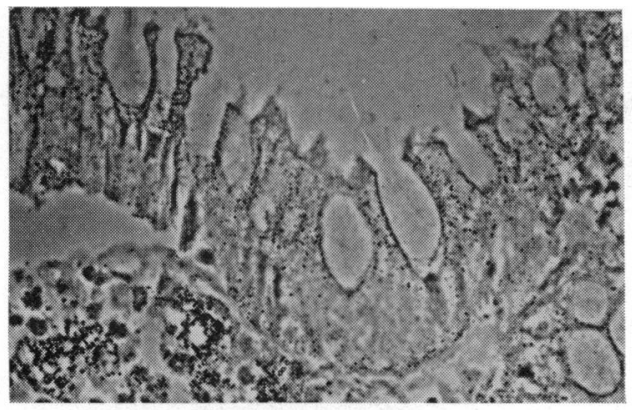

(b)

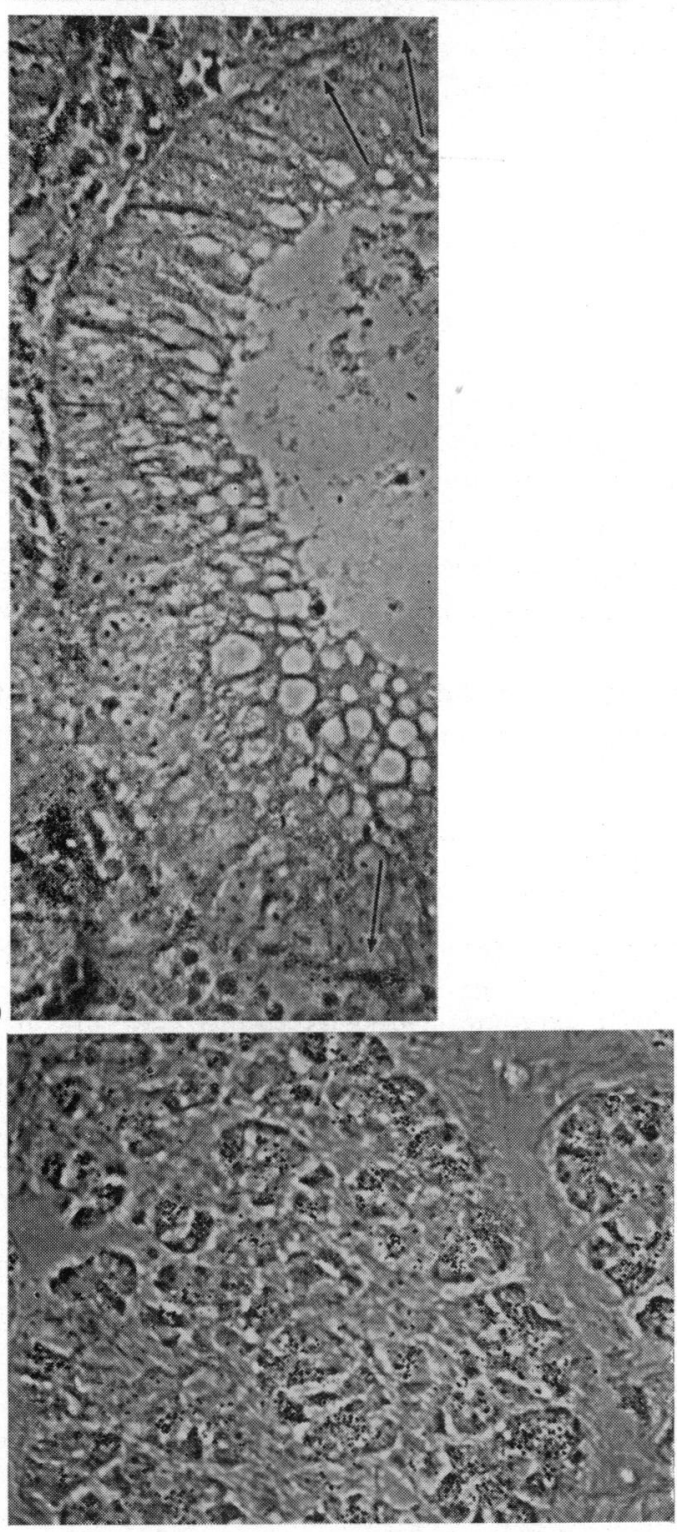

Fig. 1 Acid phosphatase activity in (a) normal mucosa, (b) polyp, and (c) carcinoma. There is a marked increase of enzyme activity in localized basal areas (arrows), and a decrease in supranuclear regions of the cells of the polyp as compared with the normal mucosa $\times 350$. Incubation time 60 minutes. (All photographs are of unstained sections. Figures 1, 2 and 4 were taken using phase contrast microscopy; in Fig. 3 a bright field was used.) investigated using Burstone's methods (1958): $\beta$-glucuronidase was investigated using the method of Hayashi, Nakajima, and Fishman (1964). Control sections were incubated in the absence of the substrate, or kept in distilled water at $\vec{\Rightarrow}$ $100^{\circ} \mathrm{C}$ for 10 minutes before incubation in the $\stackrel{?}{\rightarrow}$ full medium. In the case of acid phosphatase, sections were also incubated in the full medium $\frac{\overline{\bar{N}}}{\overline{0}}$ containing $10^{-3} \mathrm{M}$ sodium molybdate (final $\frac{\infty}{\widehat{D}}$ concentration) (Maggi, Franks, and Carbonell, $\unrhd$ 1966). After incubation the sections were rinsed is in distilled water and mounted in polyvinyl- $\vec{\circ}$ pyrrolidone (Burstone, 1958). Paraffin sections were dewaxed and stained with haematoxylin and eosin.

\section{Results}

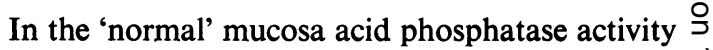
was present in the cells of the lamina propria and $\vec{\nabla}$ around the mucin droplets of the numerous goblet cells; little activity was present at the base of the epithelium (Figure 1a). In the polyp, $\vec{\varphi}$ activity appeared somewhat decreased around the mucin droplets of the goblet cells but was present at the base of these cells (Figure 1b). In the cancer tissue, activity was present also in the $\bar{\partial}$ invading and proliferating cells (Figure 1c). In ڤ all cases activity was inhibited completely by $\mathbb{\perp}$ sodium molybdate and was absent in the controls.

\section{$\beta$-GLUCURONIDASE}

The activity was very low and had a distribution and behaviour similar to that described for acid phosphatase in the 'normal' mucosa (Fig. 2a); in the polyps the basal activity was particularly evident and had increased remarkably when compared to the 'normal' tissue (Fig. 2b); in the cancer there was a marked decrease of activity which in certain areas was absent.

\section{ESTER ASES}

The behaviour of this enzyme was similar to that $N$ described for $\beta$-glucuronidase; the activity was $\underset{\sigma}{\sigma}$ high in the 'normal' epithelium in the apical areas of the epithelial cells and in the cells of the lamina propria but was scarcely present in the basal parts (Fig. 3a); in the polyp epithelium, 0 however, the basal activity was prominent $\overrightarrow{0}$ (Figure 3b). The cells of the cancer showed a decreased activity compared with the normal and the adenomatous tissues (Figure 3c).

\section{ALKALINE PHOSPHATASE}

In the 'normal' mucosa and in the polyps this enzyme was present only in the capillaries; there was little or no observable activity in the epithelium, the connective tissue, or muscle cells in 


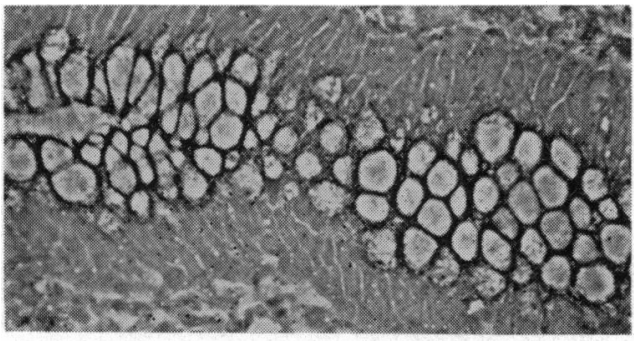

(a)

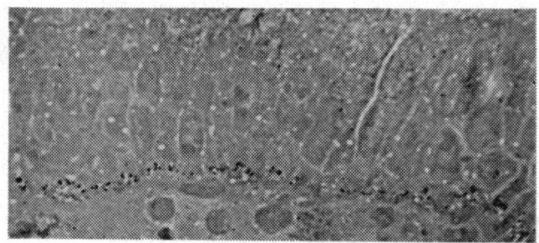

(b)

Fig. $2 \quad \beta$-glucuronidase activity in (a) normal mucosa and (b) polyp. Note the presence of activity in the basal regions and the absence of activity in the rest of the epithelium of the polyp; in the normal mucosa activity is very intense in the membranes of the mucin droplets of the goblet cells. $\times 350$. Incubation time 60 minutes.

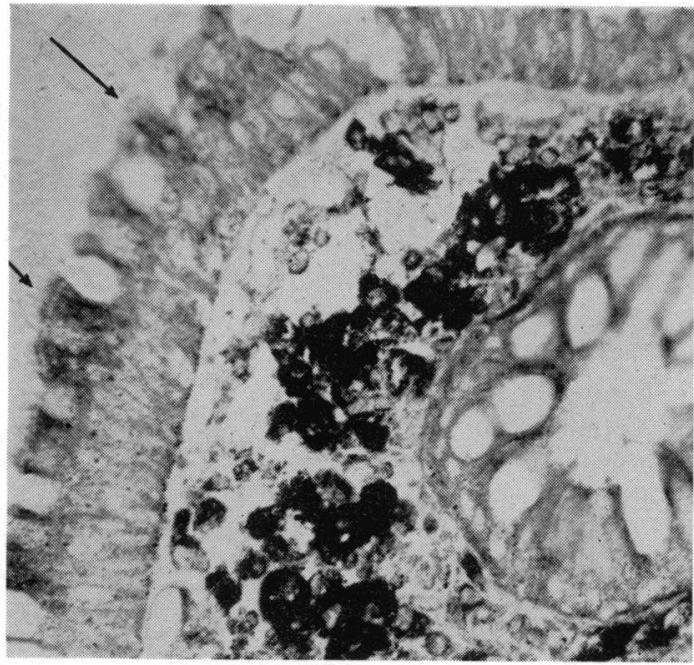

(a)

Fig. 3 Esterase activity in (a) normal mucosa, (b) polyp, and (c) carcinoma. In (a) activity is very intense in the cells of the lamina propria and in the supranuclear region of the epithelial cells (arrow). In (b) the cells of the lamina propria are less active than in (a) but the epithelial cells are more active, especially in basal regions (double arrow). In (c) activity is moderate. $\times 350$. Incubation time 20 minutes. either of these structures (Figure 4a and b). In the cancer, invading and proliferating cells contained high enzyme activity, predominantly in the form of granules (Figure 4c). Alkaline phosphatase was also present at the junction between the epithelium of the mucosa and the lamina propria, and in a number of cells of the lamina propria and in the muscularis mucosa (Figure 4d).

\section{Discussion}

Two phenomena were observed in the colon of the patient described here. First, the appearance of alkaline phosphatase activity in the cancer tissue, in the base of the epithelium, the cells of the lamina propria and, muscle cells, regions which would not be expected to contain this enzyme; and second, the appearance of acid phosphatase, $\beta$-glucuronidase, and esterase activity at the base of the epithelium of the adenomatous polyps, which was absent from the base of the 'normal' epithelium. The first finding appears to be similar to that described by Fishman, Inglis, Green, Anstiss, Gosh, Reif, Rustigian, Krant, and Stolbach (1968) and by Fishman, de Lellis, and Bluestein (1969), who found both biochemically and histochemically a

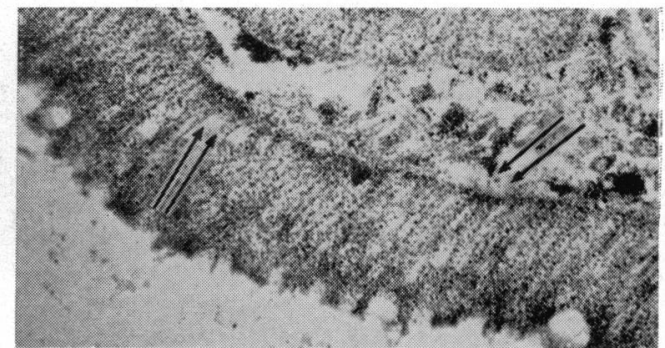

(b)

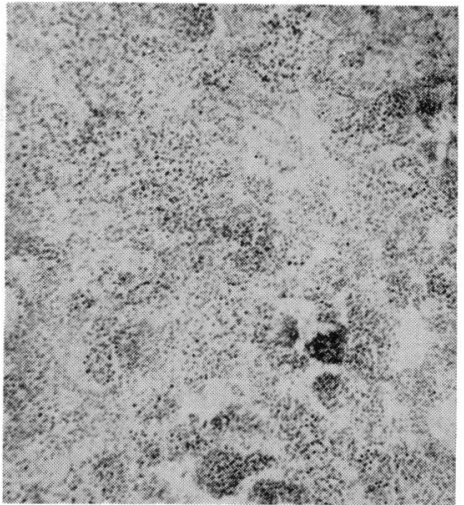

(c) 


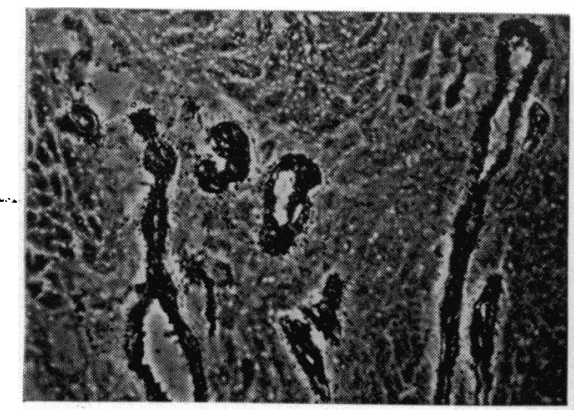

(a)

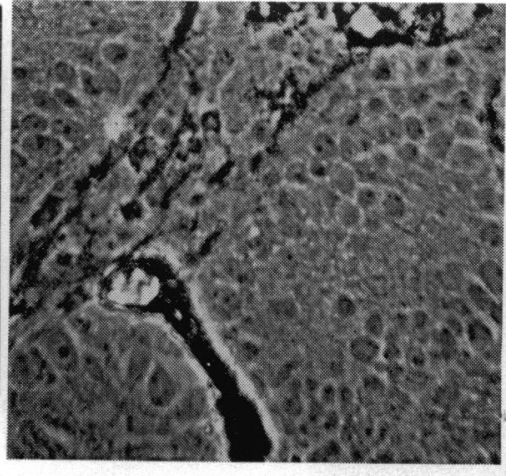

(b)

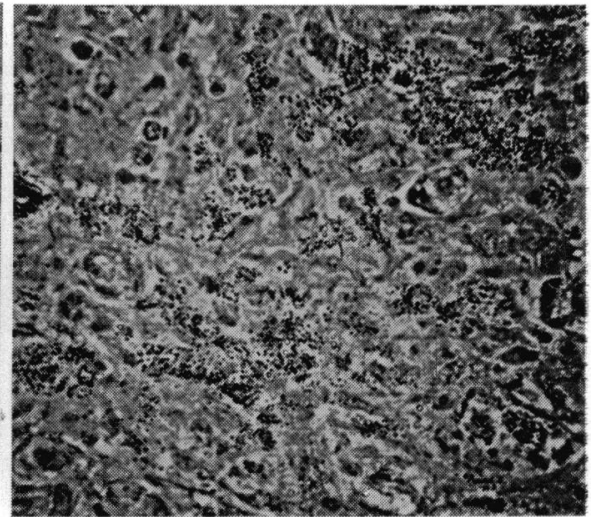

(c)

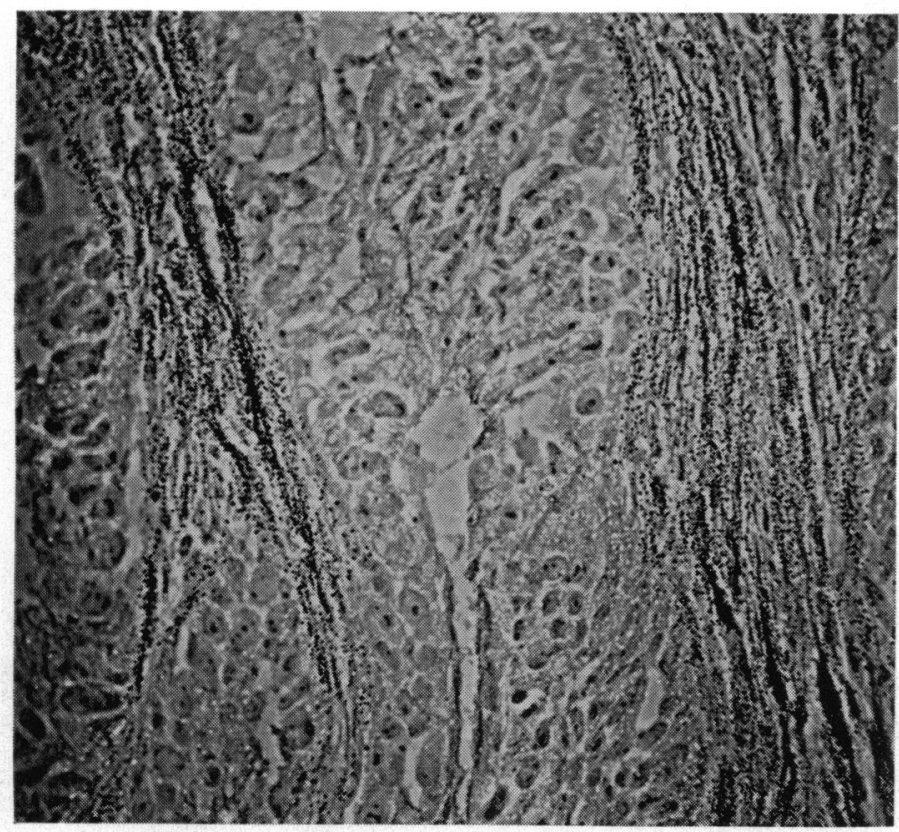

(d)
Fig. 4 Alkaline phosphatase activity in (a) normal mucosa, (b) polyp, (c) and (d) carcinoma. In (a) and (b) activity is predominantly confined to capillaries; there is no activity in the epithelium (empty areas in (a) are due to freezing damage). In (c) the invading cells show considerable activity, which is in the form of granules. Activity is also present in a particulate form in smooth muscle cells traversing a still relatively differentiated tumour area which is itself inactive (d). $\times 350$. Incubation time 60 minutes.

We wish to express our gratitude to Dr M. G. P. Stoker, Dr L. M. Franks, and Dr G. R. N. Jones for their advice in discussing this paper. We thank the late Mr A. E. Wheatley for details of the patient and access to the material; Mr G. D. Leach for processing of the photographs, and Mr M. E. Brown for technical assistance.

\section{References}

placental type of alkaline phosphatase in the serum and cancer tissues of patients with different types of carcinoma. The authors suggested a mechanism of de-repression of the placental enzyme at the genome level in cancer cells; whether this or other possible mechanisms were operating in the case described by us is impossible to ascertain. In colonic carcinoma of patients with no history of familial polyposis, alkaline phosphatase has been found similar to that of the normal tissue (Maggi and Wyatt, unpublished observations), and it would appear therefore that the data presented in this paper represent a characteristic of carcinoma developing in cases of familial polyposis of the colon. The second group of findings may indicate that acid hydrolases are enzymes involved in the breaking down of the connective tissue surrounding the polyps, thus facilitating its invasion by cancer cells.
Burstone, M. S. (1958). Histochemical comparison of naphthol AS-phosphates for the demonstration of phosphatases. J. nat. Cancer Inst., 20, 601-615. Regan isoenzyme of alkaline phosphatase in human cancer cells. J. Histochem. Cytochem., 17, 199.

Fishman, W. H., Inglis, N. R., Green, S., Anstiss, C. L., Gosh, N. K., Reif, A. E., Rustigian, R., Krant, M. J., and Stolbach, L. L. (1968). Immunology and biochemistry of Regan isoenzyme of alkaline phosphatase in human cancer. Nature (Lond.), 219, 697-699.

Hayashi, M., Nakajima, V., and Fishman, W. H. (1964). The cytologic demonstration of beta-glucuronidase employing naphthol AS-BI glucuronide and hexazonium pararosanilin; a preliminary report. J. Histochem. Cytochem., 12, 293-297. methods for enzymes and their bearing upon the Gomori acid phosphatase technique. Exp. Cell. Res., suppl. 7, 1-27.

Lockhart-Mummery, H. E. (1967). Intestinal polyposis: the present position. Proc. roy. Soc. Med., 60, 381-388.

Maggi, V., Franks, L. M., and Carbonell, A. W. (1966). Histochemical study of a number of hydrolases, including a new acid phosphatase, in various tissues of men and mice. Histochemie, 6, 305-316.
Fishman, W. H., de Lellis, D., and Bluestein, M. (1969). The

Holt, S. J. (1959). Factors governing the validity of staining อ 운 으 